\title{
ARTIGO - A MEDIAC̣̃̃O PEDAGÓGICA NA ESCRITA INVENTADA DE CRIANCAS NO PROCESSO DE ALFABETIZACÃO: PALAVRAS COM ESTRUTURA SILÁBICA CVC E CV NASAL
}

\author{
VALÉRIA BARBOSA DE RESENDE' \\ ORCID: https://orcid.org/0000-0003-1799-9618 \\ DANIELA FREITAS B. MONTUANI' \\ ORCID: https://orcid.org/0000-0001-8501-541X
}

I Universidade Federal de Minas Gerais, Faculdade de Educação,Belo Horizonte, MG, Brasil.

Valéria B. de Resende - Doutora em Educação pela Universidade Federal de Minas Gerais e Pós-doutorado pelo Instituto Universitário de Ciências Psicológicas, Sociais e da Vida (ISPA) Lisboa, Portugal. Professora da Faculdade de Educação da UFMG e pesquisadora do Centro de Alfabetização, Leitura e Escrita CEALE/FaE/UFMG. E-mail:<valeriaresende2@gmail.com>.

Daniela F. B. Montuani - Doutora em Educação pela Universidade Federal de Minas Gerais. Professora da Faculdade de Educação da UFMG e pesquisadora do Centro de Alfabetização, Leitura e Escrita - CEALE/ FaE/UFMG. E-mail:<danimontuani@gmail.com >.

RESUMO: Neste artigo, analisamos os efeitos da mediação pedagógica do adulto na escrita inventada de palavras compostas por sílabas com estrutura consoante-vogal-consoante (CVC) e consoante-vogal nasal (CV nasal), realizada por crianças de 6 anos de uma escola pública. Trata-se de uma pesquisa de intervenção que, segundo Spinillo e Lautert (2009), visa a um engajamento do pesquisador com a realidade educacional, oferecendo evidências para a construção de modelos teóricos e para a transformação da prática. Foi desenvolvido um Programa de Escrita Inventada (ALVES MARTINS, 2017), com a realização de 10 sessões com grupos de quatro crianças. O estudo revelou um avanço das crianças na escrita de palavras com as estruturas silábicas investigadas. Ademais, foi possível identificar não só as estratégias de mediação (scaffolding) nomeadas em sete categorias principais (Gestão, Instrução, Indagação, Sinalização, Elaboração, Reelaboração e Avaliação), bem como o predomínio de algumas delas nas sessões (Indagação, Gestão, Sinalização e Elaboração), demonstrando sua importância para o processo de aprendizagem da língua escrita.

Palavras-chave: Mediação pedagógica. Escrita inventada. Alfabetização de crianças. 


\section{THE PEDAGOGICAL MEDIATION IN THE INVENTED WRITING OF CHILDREN IN THE PROCESS OF LITERACY: WORDS WITH COMPLEX STRUCTURE}

ABSTRACT: In this article we analyze the effects of adult pedagogical mediation on the invented writing of words composed by syllables with consonant-vowel-consonant structure (CVC) and nasal vowel-consonant (nasal CV) by 6-year-old children of a public school. It is an intervention research, which according to Spinillo and Lautert (2009) aims at an engagement of the researcher with the educational reality, offering evidence for the construction of theoretical models and transformation of practice. An Invented Writing Program was developed (Alves Martins, 2017) with 10 sessions with groups of four children. The study revealed an advance of children in word writing with the syllabic structures investigated. In addition, it was possible to identify mediation strategies (the scaffolding) named in seven main categories (Management, Instruction, Inquiry, Signaling, Elaboration, Re-elaboration and Evaluation) as well as the predominance of some of them in the sessions (Inquiry, Management, Signaling and Elaboration) its importance for the learning process of written language.

Keywords: Pedagogical mediation. Invented writing. Children's literacy.

\section{INTRODUĈ̣̃O}

Neste artigo, apresentaremos a descrição e a análise de parte dos dados de uma pesquisa de intervenção, ${ }^{1}$ tendo como foco os efeitos da mediação pedagógica do adulto na escrita inventada de palavras com estrutura silábica CONSOANTE - VOGAL - CONSOANTE (CVC) e CONSOANTE - VOGAL NASAL $(\mathrm{CV}[$ nasal $]){ }^{2}$ A escolha por palavras com essas estruturas silábicas se deu devido ao conhecimento de que, conforme apontado por Soares (2016), no processo inicial de aprendizagem da língua escrita, as crianças compreendem o princípio alfabético basicamente pela sílaba canônica do português (CV), enfrentando dificuldades na representação de sílabas complexas e na representação da nasalidade das vogais. Portanto, analisar as estratégias de mediação das sessões de escrita inventada para compreensão da apropriação pelas crianças de palavras dessa natureza se tornou um dos nossos objetivos.

A pesquisa foi desenvolvida com crianças que, no início da investigação, em março de 2018, apresentavam a idade média de 6 anos e 4 meses e encontravam-se em diferentes hipóteses de escrita, conforme percurso evolutivo descrito por Ferreiro \& Teberosky (1985). Essas crianças frequentavam o $1^{\circ}$ ano do Ensino Fundamental em uma Escola Estadual situada na região central de Belo Horizonte, Minas Gerais. 
Este trabalho enquadra-se nas investigações desenvolvidas pelo Grupo de Pesquisa em Alfabetização (GPA/CEALE/UFMG), que, em parceria com outras duas instituições - Instituto Universitário de Ciências Psicológicas, Sociais e da Vida (ISPA) Lisboa, Portugal e Universidade Federal de Pernambuco (UFPE) -, propuseram desenvolver um projeto coletivo internacional envolvendo o "Programa de Escrita Inventada". O GPA tem investido em pesquisas que analisam a mediação do adulto em Programas de Escrita Inventada na Educação Infantil, nos anos iniciais do Ensino Fundamental e na Educação de Jovens e Adultos.

As investigações que apresentam como metodologia o uso do "Programa de Escrita Inventada" foram desenvolvidas pioneiramente por Alves Martins e colaboradores (2012, 2015, 2017a, 2018). Nesses estudos experimentais, o foco principal é analisar os efeitos do programa e as mediações efetuadas pelos adultos durante as atividades de escrita inventada, envolvendo crianças da pré-escola, com idade de 5 anos. Os resultados revelam que a articulação entre a escrita inventada que expõe as formas de pensamento das crianças sobre o sistema de escrita e a mediação do adulto promove o avanço da consciência fonológica e fonêmica das crianças, potencializando o sucesso na alfabetização.

Alves Martins e Albuquerque (2017b) também realizaram um estudo comparativo para avaliar os efeitos de um Programa de Escrita Inventada na aprendizagem de habilidades iniciais de alfabetização em crianças pré-escolares falantes de língua portuguesa em Portugal (português europeu) e no Brasil (português brasileiro). A intenção foi verificar se os resultados positivos observados nos programas desenvolvidos em Portugal poderiam ser alargados a outra variante linguística do mesmo idioma, considerando que a língua portuguesa não é homogênea e apresenta diferenças fonológicas, lexicais e sintáticas marcantes.

Ao comparar os resultados do pré-teste e do pós-teste, ficou evidente o avanço tanto dos participantes portugueses quanto dos brasileiros na habilidade de decodificação de alguns fonemas, lendo corretamente determinados segmentos das palavras e, em alguns casos, inclusive, as palavras na sua totalidade. $O$ estudo sugere que as atividades de escrita inventada, além de promover a aquisição do princípio alfabético, também favoreceu a transferência de novos conhecimentos metalinguísticos para as habilidades de leitura de crianças falantes de duas variantes do português: europeu e brasileiro (ALVES MARTINS e ALBUQUERQUE, 2017b).

Os estudos citados anteriormente ancoram-se no conceito de "escrita inventada", inicialmente introduzido por Read $(1971$; 1975) e 
por Chomsky (1971), e diz respeito às escritas "precoces" das crianças antes mesmo do domínio das convenções do sistema de escrita e do ingresso no ensino formal. Essas escritas, segundo os autores, não são resultantes de uma cópia, mas tentativas criativas de representar a escrita, a partir das explorações e interpretações subjetivas que as crianças fazem do sistema de escrita e de suas convenções. Essas produções precoces das crianças são relevantes para a compreensão do pensamento infantil e de suas formas de representação.

Nessa linha de pensamento, os estudos de Ferreiro e Teberosky (1985) consideram como premissas do trabalho investigativo a competência linguística da criança e suas capacidades cognoscitivas e, com base no referencial piagetiano, as autoras demonstraram que as crianças levantam hipóteses sobre a escrita, mesmo antes de iniciar a aprendizagem formal. Ferreiro (2001, p.19) detalha o desenvolvimento da escrita de crianças falantes do espanhol e apresenta três grandes períodos desse processo, que ela define como a "reinvenção" da escrita pela criança: 1) distinção entre o modo icônico e não-icônico; 2) a construção de formas de diferenciação (controle progressivo das variações sobre os eixos qualitativo e quantitativo); e 3) a fonetização da escrita (que se inicia com um período silábico, passando pela hipótese silábico-alfabética e culmina no período alfabético). Isso significa que, em um primeiro momento, a criança não estabelece nenhuma relação consistente entre linguagem oral e escrita (hipótese pré-silábica), passando pela fase da "fonetização da escrita", em que a criança elabora várias hipóteses sobre o funcionamento do sistema de escrita: uma letra para cada sílaba (hipótese silábica), letras indicando sílabas e letras indicando fonemas em uma mesma palavra (hipótese silábico-alfabética) e correspondências mais consistentes entre grafemas/fonemas (hipótese alfabética).

Detalharemos um pouco mais sobre o processo de "fonetização da escrita", considerando que o público da pesquisa se encontra, predominantemente, nessa fase e também é o período em que a criança descobre as relações sonoras entre escrita e linguagem falada. Na hipótese silábica, a criança faz uso de uma letra para cada sílaba da palavra. Inicialmente não há correspondência sonora, em seguida, a criança usa letras com valor sonoro representando um dos fonemas da sílaba. Teberosky (1989) evidencia que, na hipótese silábica, é possível encontrar duas possibilidades de representação:

Com correspondencia cuantitativa según un análisis sonoro del lenguaje que lleva al niño a descubrir la sílaba como unidad sobre la cual se puede establecer la correspondencia (a cada sílaba le corresponde una grafía). La correspondencia 
cualitativa se adquiere a partir del aprendizaje de los valores sonoros convencionales. Se abandona la correspondencia exclusivamente cuantitativa en favor de uma correspondencia cualitativa; determinadas letras "valen" para determinadas sílabas. (TEBEROSKY, 1989, p. 166).

A hipótese silábico-alfabética pode ser considerada como uma fase de transição e é descrita por Ferreiro (2013) como um período de desestabilização das escritas silábicas, quando a criança começa a perceber que a sílaba não é a unidade menor da palavra, mas esse conhecimento ainda não foi consolidado: "algumas sílabas são escritas com uma única letra, como no período precedente, mas outras sílabas são escritas com mais de uma letra, anunciando, ao que parece, o abandono da análise silábica" (FERREIRO, 2013, p.65).

$\mathrm{Na}$ hipótese alfabética, as palavras são representadas estabelecendo relações entre grafemas e fonemas. Nessa hipótese a criança ainda enfrenta dificuldades com relação à análise fonêmica, entretanto, para as autoras, terminam os problemas de ordem conceitual e iniciam os problemas de ordem ortográfica.

Dentro de uma perspectiva fonológica, Ehri (apud, SOARES 2016), tendo como referência o sistema de escrita alfabética e não o pensamento infantil, como fez Ferreiro e Teberosky, também descreve fases do desenvolvimento da linguagem escrita: 1) fase préalfabética: combinação de letras de forma arbitrária; 2) fase parcial: início da representação de alguns sons e sílabas; 3) fase alfabética: correspondência sistemática entre letras e sons; e 4) fase alfabética consolidada: consideram as convenções ortográficas e podem ser considerados leitores e escritores proficientes. Podemos estabelecer alguns paralelos entre Ferreiro e Ehri, que contribuem para entender as escritas das crianças que nem sempre são homogêneas, ou seja, escritas de uma mesma criança em uma mesma época que podem ser enquadradas em diferentes níveis.

Dentro de uma perspectiva semiótica, Vygotsky (1991) também contribui para o entendimento da história do desenvolvimento dos signos na criança, que considera o aparecimento dos gestos como um signo visual, os rabiscos, os desenhos, as brincadeiras, os jogos de faz de conta. Esses elementos são fundamentais para compreender o processo de construção da representação simbólica até culminar na linguagem escrita. Para o autor, a descoberta básica que a criança precisa fazer é "a de que se pode desenhar, além de coisas, também a fala” (VYGOTSKY, 1991, p.76).

Para Vygotsky, o foco é o uso da escrita pela criança, numa perspectiva semiótica; para Ferreiro, o foco é posto nos processos 
cognitivos da criança, numa perspectiva psicogenética; e Ehri baseiase em evidências fonológicas. Essas diferentes perspectivas de análise contribuem para ampliar o foco de análise das escritas produzidas pelas crianças e compreender o processo de apropriação do sistema de escrita alfabética em bases teóricas diversas, porém complementares.

Um outro aspecto em destaque em nossa pesquisa diz respeito à descrição e à análise das estratégias utilizadas pelo adulto para mediar a interação com as crianças durante as atividades de escrita inventada. Alves Martins (2017a) mostrou, em seu estudo, que expor as crianças em situações nas quais elas precisem argumentar e envolver-se na construção de uma solução coletiva para um problema na escrita favorece o desenvolvimento da consciência fonêmica e a compreensão da lógica da escrita alfabética. Os resultados revelaram a eficácia dos Programas de Escritas Inventadas para a aprendizagem e a construção da autonomia das crianças, porque elas são levadas a compreender a lógica do funcionamento do grupo, expor ideias, confrontar, argumentar, confirmar ou refutar hipóteses.

Para compreender a mediação adulto-criança, vamos lançar mão do conceito de scaffolding, termo cunhado de Wood, Bruner e Ross (1976). O termo é uma metáfora, cuja tradução é "colocar andaimes", tal qual usado na construção civil, e essa estrutura provisória é retirada quando a edificação está consolidada. Assim, por meio do scaffolding, pode-se elaborar um rol de estratégias visando consolidar habilidades. Esse apoio fornecido por um parceiro mais competente, na execução de uma tarefa que o aprendiz ainda não realize sozinho, é pouco a pouco retirado até que a criança alcance autonomia na sua realização.

O termo scaffolding diz respeito ao acompanhamento do desempenho da criança gerido pelo adulto, ou seja, das estratégias utilizadas pelos adultos para dar assistência ao desenvolvimento da criança, as quais, dentro da escola sociocultural, demandam sempre a participação ativa das crianças. Após a consolidação de uma determinada aprendizagem (interiorização), o apoio do adulto não é mais necessário. Nessa direção, Pontecorvo (2005, p.17) afirma que o desenvolvimento cognitivo infantil é sempre construído pela interação social e que

no início, administrada prevalentemente pelo adulto, com o oferecimento de um scaffolding, isto é, de um "andaime de sustentação", mas que, progressivamente, passa a ser "transferido" e, portanto, cada vez mais assumido e compartilhado pela criança. (PONTECORVO, 2005, p.17).

Essa estratégia pedagógica scaffolding dialoga com o conceito de Zona de Desenvolvimento Proximal (ZDP) de Vygotsky, que atribui um papel determinante à influência da interação social e 
cultural sobre o desenvolvimento da criança. Dentre os meios do desempenho assistido, Moll (1996) destaca: 1) modelagem: processo de oferecer comportamentos a serem imitados; 2) gerenciamento das contingências: recompensas, elogios e encorajamento que se sucedem a um comportamento; 3) realimentação ou feedback: orientação para correção ou manutenção de um comportamento para melhorar o desempenho em uma próxima tentativa; 4) instrução: instruções efetivas contextualizadas; 5) questionamento: perguntas que exijam uma resposta cognitiva e linguística ativa; 6) estrutura cognitiva: provimento de uma forma de pensamento e ação.

Dentro da perspectiva vygostkiana, o ensino é algo que possibilita atuar na zona de desenvolvimento proximal, que vai do desempenho assistido ao desempenho não assistido e autorregulado, passando por quatro estágios, segundo Moll (1996, p.180): 1) o desempenho é assistido por indivíduos mais capazes, ou seja, para desempenhar uma tarefa, a criança ainda depende do auxílio de um adulto ou colega mais capaz; 2) o desempenho é autoassistido, isto é, a criança já consegue executar a tarefa sem assistência externa; 3) o desempenho é desenvolvido, automatizado e fossilizado, e passa do plano interpsicológico para o intrapsicológico; 4) o desempenho é desautomatizado e conduz a um retorno à zona de desenvolvimento proximal. Em todo processo de aprendizagem, haverá oscilações entre formas de autocontrole e de controle externo.

A partir do conceito de scaffolding cunhado por Wood, Bruner e Ross (1976), revisitado por Moll (1996), Pontecorvo (2005) e Alves Martins (2017), podemos ampliar o entendimento de Zona de Desenvolvimento Proximal de Vygostsky, que considera o papel da interação social na aquisição do conhecimento, do trabalho em colaboração adulto-criança, visando favorecer a aprendizagem e, no caso específico da nossa pesquisa, a aprendizagem das correspondências grafofônicas. Assim, descrever os modos de realizar scaffolding é fundamental para as investigações que tratam da mediação nos programas de escrita inventada.

\section{METODOLOGIA}

Trata-se de uma pesquisa de intervenção acerca do papel da interação social no processo de desenvolvimento da criança. É importante salientar que usamos o termo interação social no sentido vygotskiano em que a dimensão social e a individual se unem pela interação por meio da argumentação. 
Os estudos de Spinillo e Lautert (2009) mostram as possibilidades e os desafios da pesquisa de intervenção no âmbito da psicologia do desenvolvimento cognitivo. Dentre as contribuições, citamos a possibilidade de descrever o desenvolvimento humano e descobrir relações de causalidade entre fatores e fenômenos, e promover algum tipo de mudanças, "sendo, ainda, marcadas por uma relação assimétrica em que um dos participantes desta relação é aquele que assiste, propõe e encaminha atividades a serem realizadas" (SPINILLO e LAUTERT, 2009, p. 299).

O estudo explora as relações entre um Programa de Escrita Inventada e seus efeitos na escrita de palavras compostas por estrutura silábica complexa (CVC) e CV [nasal]. O uso da metodologia do Programa de Escrita Inventada se justifica, considerando os resultados obtidos por Alves Martins em diversos estudos (2012, 2015, 2017), visto que

\footnotetext{
as atividades de escrita inventada são um instrumento importante de ajuda à compreensão do princípio alfabético, na medida em que, quando tentam escrever, as crianças são levadas a pensar na linguagem oral e nos sons que a constituem, na linguagem escrita, e nas letras que a compõem e nas relações entre ambas. (ALVES MARTINS, 2015).
}

\section{PARTICIPANTES}

Participaram da pesquisa 16 crianças, que se encontravam na fase de fonetização da escrita e foram organizadas da seguinte forma: três grupos compostos por crianças com idade de 6 anos, sendo 8 meninas e 4 meninos que frequentavam o $1^{\circ}$ ano do Ensino Fundamental, e um grupo composto por 4 meninas que frequentavam o $2^{\circ}$ ano do Ensino Fundamental, com idade de 7 anos. As crianças frequentavam a mesma escola da rede pública estadual da cidade de Belo Horizonte.

Os dados que serão descritos e analisados neste artigo foram extraídos de um dos grupos composto por crianças de 6 anos, sendo 3 meninas e 1 menino. Todas as meninas frequentaram Pré-escola e o menino não frequentou esse nível de ensino. A escolha desse grupo se deu pelos critérios de assiduidade dos integrantes em todas as sessões e pela disposição para desenvolver o trabalho colaborativo, tendo em vista que analisar as interações e as mediações com as crianças se constituiu como principal objetivo.

\section{PRÉ-TESTE, PÓS-TESTE E PÓS-TESTE POSTERGADO}

As crianças foram submetidas individualmente, sem nenhuma intervenção do adulto, a avaliações envolvendo a escrita de 12 
palavras, antes e após a realização do Programa de Escrita Inventada. Essas avaliações, que doravante serão denominadas de pré-teste, pósteste e pós-teste postergado, foram aplicadas pela pesquisadora e pela auxiliar de pesquisa, ${ }^{3}$ mantendo-se a mesma ordem, nas seguintes ocasiões: o pré-teste, aplicado no dia 27/03/2018; o pós-teste, no dia 08/05/2018; e o pós-teste postergado, no dia 07/08/2018. As palavras usadas nas avaliações apresentavam diferentes estruturas silábicas do português brasileiro (CV, CV[nasal], CVC, CCV), e, como mencionado anteriormente, neste artigo daremos destaque às escritas das palavras com estrutura CVC e CV[nasal].

\section{AS SESSÕES DO PROGRAMA DE ESCRITA INVENTADA}

As atividades de escrita inventada colaborativa foram desenvolvidas em pequeno grupo formado por 4 crianças, tendo um adulto como mediador. Os encontros foram realizados duas vezes por semana, durante 5 semanas. Cada sessão tinha a duração de 15 a 20 minutos, e as crianças eram instadas a discutir entre si, expor, argumentar e chegar a um acordo sobre as letras que deveriam ser usadas para escrever a palavra ditada pelo adulto.

As palavras ditadas foram extraídas de textos da literatura infantil (quadrinhas, trava-línguas, parlendas e histórias), com a intenção de garantir que as crianças soubessem os seus significados e seu contexto de uso. Nas primeiras sessões, o adulto é que fazia o registro das palavras; a partir da sexta sessão, a mediadora indicava uma das crianças do grupo para realizar o registro da palavra no papel. A criança era orientada a registrar somente as letras acordadas pelo grupo. Após o término da escrita inicial de cada palavra, a mediadora apresentava a escrita convencional da palavra, alegando ter sido produzida por crianças de outra escola, e solicitava a análise comparativa das escritas, e o grupo deveria indicar a escrita que considerava correta.

Nas sessões foram utilizadas palavras dissílabas com estrutura CVC-CV, favorecendo a reflexão inicial da sílaba complexa (CVC), seguida da sílaba canônica (CV). As palavras selecionadas foram: SUSTO - CORDA - LISTA - CARNE - SURDO - GOSTO. E também foram utilizadas palavras dissílabas com estrutura silábica CV[nasal], na primeira sílaba: DENTE - LINDA - VENTO.

As dez sessões de escrita inventada foram gravadas integralmente em câmera de vídeo em suporte digital. As sessões iniciais (1), intermediárias (2) e finais (3) foram transcritas e analisadas para definição do tipo de scaffolding. Para essa definição, foram elaboradas 7 categorias e 11 subcategorias, baseadas nas 
tabelas construídas por Alves Martins et al (2017) e Salvador (2017), conforme será apresentado na análise dos dados. Foram consideradas como mensagens de intervenção aquelas unidades enunciativas com sentido pleno, que garantissem uma atitude responsiva.

\section{RESULTADOS E DISCUSSÃO}

\section{O AVANC̦O NA ESCRITA INDIVIDUAL DAS CRIANÇAS}

Com o objetivo de refletirmos sobre a mediação na escrita inventada de palavras CVC e CV[nasal], conforme apontado nos objetivos deste artigo, analisamos inicialmente o avanço das crianças participantes no pós-teste e pós-teste postergado na escrita das palavras VERDE - COSTA- PENTE, ou seja, palavras com estruturas silábicas que são o foco deste estudo.

Para a contagem dos acertos, atribuiu-se 1 ponto para cada correspondência correta fonema-grafema e foram estabelecidos os seguintes critérios:

1. Correspondência oral/escrito na posição convencional; por exemplo, na escrita da palavra COSTA, a criança usou as letras OATA e foram contabilizados 3 acertos, considerando a letra O em 'COS' e a sílaba final da palavra - TA.

2. Foi considerado acerto a letra que corresponde a uma variação dialetal, por exemplo, uso da letra I no final de palavras como em PENTE e VERDE.

3. Pontuação máxima para as palavras VERDE - COSTA PENTE é de 15 pontos.

Apresentamos a seguir as tabelas I, II, III e IV com os resultados de Camila Fernando, Marina e Sônia, ${ }^{4}$ que, como apontado anteriormente, apresentaram avanços em suas escritas.

TABELA 1. Escritas individuais de Camila

\begin{tabular}{|c|c|c|c|c|c|c|}
\hline $\begin{array}{c}\text { Palavra } \\
\text { ditada }\end{array}$ & $\begin{array}{c}\text { PRÉ-TESTE } \\
27 / 03 / 2018\end{array}$ & $\begin{array}{c}\text { Acertos corres- } \\
\text { pondência oral/ } \\
\text { escrito }\end{array}$ & $\begin{array}{c}\text { PÓS-TESTE } \\
08 / 05 / 2018\end{array}$ & $\begin{array}{c}\text { Acertos corres- } \\
\text { pondência oral/ } \\
\text { escrito }\end{array}$ & $\begin{array}{c}\text { PÓS-TESTE } \\
\text { POSTERGARDO } \\
\text { O7/08/2018 }\end{array}$ & $\begin{array}{c}\text { Acertos corres- } \\
\text { pondência oral/ } \\
\text { escrito }\end{array}$ \\
\hline VERDE & VAIP & 1 & VDI & 3 & VEDE & 4 \\
\hline COSTA & OATA & 3 & COTA & 4 & COTA & 4 \\
\hline PENTE & PETA & 3 & PETE & 4 & PETE & 4 \\
\hline Total 15 & & 7 & & 11 & & 12 \\
\hline
\end{tabular}

Fonte: Elaborado pelas autoras com os dados da pesquisa. 
TABELA 2. Escritas individuais de Fernando

\begin{tabular}{|c|c|c|c|c|c|c|}
\hline $\begin{array}{c}\text { Palavra } \\
\text { ditada }\end{array}$ & $\begin{array}{c}\text { PRÉ-TESTE } \\
27 / 03 / 2018\end{array}$ & $\begin{array}{c}\text { Acertos corres- } \\
\text { pondência orall } \\
\text { escrito }\end{array}$ & $\begin{array}{c}\text { PÓS-TESTE } \\
08 / 05 / 2018\end{array}$ & $\begin{array}{c}\text { Acertos corres- } \\
\text { pondência oral/ } \\
\text { escrito }\end{array}$ & $\begin{array}{c}\text { PÓS-TESTE } \\
\text { POSTERGARDO } \\
07 / 08 / 2018\end{array}$ & $\begin{array}{c}\text { Acertos corres- } \\
\text { pondência oral/ } \\
\text { escrito }\end{array}$ \\
\hline VERDE & DELIFIPE & 0 & VEDI & 4 & VERDE & 5 \\
\hline COSTA & FICE & 0 & COSTA & 5 & COSTA & 5 \\
\hline PENTE & FLISA & 0 & PENTI & 5 & PENTE & 5 \\
\hline Total 15 & & 0 & & 14 & & 15 \\
\hline
\end{tabular}

Fonte: Elaborado pelas autoras com os dados da pesquisa.

TABELA 3. Escritas individuais de Marina

\begin{tabular}{|c|c|c|c|c|c|c|}
\hline $\begin{array}{c}\text { Palavra } \\
\text { ditada }\end{array}$ & $\begin{array}{c}\text { PRÉ-TESTE } \\
27 / 03 / 2018\end{array}$ & $\begin{array}{c}\text { Acertos corres- } \\
\text { pondência orall } \\
\text { escrito }\end{array}$ & $\begin{array}{c}\text { PÓS-TESTE } \\
08 / 05 / 2018\end{array}$ & $\begin{array}{c}\text { Acertos corres- } \\
\text { pondência orall } \\
\text { escrito }\end{array}$ & $\begin{array}{c}\text { PÓS-TESTE } \\
\text { POSTERGARDO } \\
\text { 07/08/2018 }\end{array}$ & $\begin{array}{c}\text { Acertos corres- } \\
\text { pondência oral/ } \\
\text { escrito }\end{array}$ \\
\hline VERDE & VEDI & 4 & VERDE & 5 & VERDE & 5 \\
\hline COSTA & COSTA & 5 & COSTA & 5 & COSTA & 5 \\
\hline PENTE & PEDE & 3 & PETE & 4 & PENTE & 5 \\
\hline Total 15 & & 12 & & 14 & & 15 \\
\hline
\end{tabular}

Fonte: Elaborado pelas autoras com os dados da pesquisa.

TABELA 4. Escritas individuais de Sônia

\begin{tabular}{|c|c|c|c|c|c|c|}
\hline $\begin{array}{c}\text { Palavra } \\
\text { ditada }\end{array}$ & $\begin{array}{c}\text { Produção } \\
\text { escrita } \\
\text { PRÉ-TESTE } \\
27 / 03 / 2018\end{array}$ & $\begin{array}{c}\text { Acertos corres- } \\
\text { pondência oral/ } \\
\text { escrito }\end{array}$ & $\begin{array}{c}\text { Producão escrita } \\
\text { PÓS-TESTE } \\
\text { 08/05/2018 }\end{array}$ & $\begin{array}{c}\text { Acertos corres- } \\
\text { pondência orall } \\
\text { escrito }\end{array}$ & $\begin{array}{c}\text { Produção escrita } \\
\text { PÓS-TESTE } \\
\text { POSTERGARDO } \\
\text { 07/08/2018 }\end{array}$ & $\begin{array}{c}\text { Acertos corres- } \\
\text { pondência orall } \\
\text { escrito }\end{array}$ \\
\hline VERDE & VRDI & 4 & VERDI & 5 & VERDE & 5 \\
\hline COSTA & COSTA & 5 & COSTA & 5 & COSTA & 5 \\
\hline PENTE & PEIDE & 3 & PENTE & 5 & PENTI & 5 \\
\hline Total 15 & & 12 & & 15 & & 15 \\
\hline
\end{tabular}

Fonte: Elaborado pelas autoras com os dados da pesquisa.

Ao analisar os resultados expostos nas tabelas I, II, III e IV, ficam evidenciados avanços no processo de apropriação do sistema de escrita alfabética de todas as crianças, após frequentarem as sessões do Programa de Escrita Inventada.

Nota-se que Camila (tabela I) apresentou no pré-teste a capacidade de identificar alguns fonemas que compõem a palavra; algumas letras são usadas com correspondência, como as consoantes 
' $\mathrm{V}$ ' e ' $\mathrm{T}$ ', entretanto, se analisarmos a primeira escrita da palavra $V E R D E$, não há consistência no uso das vogais e tampouco no uso da letra 'P'. A criança também utiliza o padrão de 4 letras para a escrita de todas as palavras avaliadas. No pós-teste, Camila demonstra avanço e adequadas correspondências grafemas/fonemas, entretanto ainda não é capaz de registrar as sílabas complexas, reduzindo-as ao padrão $C V$, como em COT $A$ para COST $A$ e também não faz a marcação da nasalidade na escrita de PENTE e escreve PETE. Nos dois primeiros testes, para a palavra VERDE, a criança registra apenas a letra V para grafar a sílaba VE (princípio acrofônico); ${ }^{5}$ isso já não acontece no pós-teste postergado, mas a criança ainda mantém o padrão CV na escrita das palavras, e percebe-se que, apesar de acertos em algumas correspondências, não houve avanço no registro das sílabas complexas com estrutura CVC.

O percurso de Fernando (tabela II) chama a atenção devido ao perceptível avanço no processo de apropriação da escrita, uma vez que, no pré-teste, não apresentou nenhuma correspondência letrasom, entretanto no pós-teste mostrou-se capaz de registrar todos os sons que compõem as palavras, exceto para a palavra VERDE, que foi grafada dentro do padrão CV - VEDI. E ainda no pós-teste postergado, Fernando produz as escritas ortograficamente corretas.

As escritas produzidas por Marina no pré-teste mostram a sua capacidade de correspondência grafofonêmica, entretanto essa correspondência não ocorre no registro de todas as sílabas, como pode ser percebido nas palavras VERDE (VEDI) e PENTE $(P E D E)$. Essa habilidade é ampliada após o programa, à exceção apenas do registro da letra $\mathrm{N}$ em PENTE. No entanto, verifica-se, no pós-teste postergado, que houve a apropriação desse conhecimento.

Sônia é a criança que apresentava mais avanço no processo de apropriação da escrita antes de iniciar o Programa de Escrita Inventada, e já no pré-teste revela a intencionalidade de registro das sílabas complexas, apesar de não usar todas as letras com sua equivalência sonora convencional com a escrita de PEIDE para PENTE. Nesse registro, há dúvidas com relação à letra a inserir para grafar a nasalização da vogal e há trocas surdo-sonora - T e D. Entretanto, no pós-teste e pós-teste postergado, a criança demonstra capacidade para grafar as sílabas com estrutura CVC e CV[nasal].

$\mathrm{Na}$ tabela e gráfico a seguir, é possível quantificar os acertos de cada criança e visualizar os avanços considerando os percursos individuais. 
TABELA 5. Quantitativo de acertos nas avaliações individuais

\begin{tabular}{|c|c|c|c|}
\hline & $\begin{array}{c}\text { Pré-teste } \\
\text { acertos }\end{array}$ & $\begin{array}{c}\text { Pós-teste } \\
\text { Acertos }\end{array}$ & $\begin{array}{c}\text { Pós-teste } \\
\text { postergado } \\
\text { acertos }\end{array}$ \\
\hline Camila & 7 & 11 & 12 \\
\hline Fernando & 0 & 14 & 15 \\
\hline Marina & 12 & 14 & 15 \\
\hline Sônia & 12 & 15 & 15 \\
\hline
\end{tabular}

Fonte: Elaborado pelas autoras com os dados da pesquisa.

GRÁFICO 1. Percursos individuais e acertos nas fonetizações

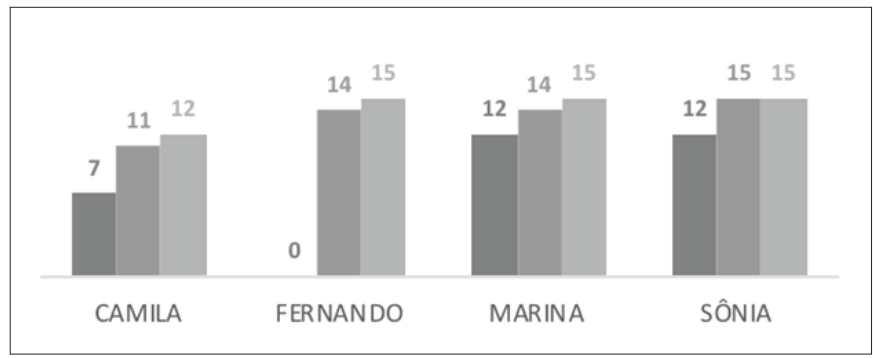

Fonte: Elaborado pelas autoras com os dados da pesquisa.

A tabela $\mathrm{V}$ mostra que $75 \%$ das crianças consolidaram habilidades envolvendo a estrutura silábica CVC nas palavras contendo fonemas representados pelas letras $\mathrm{R}$ (rótica), $\mathrm{S}$ (fricativa) e CV [nasal]. A criança que ainda não consolidou essa habilidade demonstrou ter avançado no processo de apropriação da escrita. Esses resultados evidenciam que os percursos individuais são, de certa forma, heterogêneos e com ritmos diferenciados, como mostrado no gráfico I.

\section{TIPOS DE SCAFFOLDING NO PROCESSO DE MEDIAC̣ÃO}

Neste tópico apresentaremos as categorias de mediação compreendidas nas três sessões de escritainventada (inicial, intermediária e final), totalizando 9 episódios. Esses episódios foram selecionados, considerando os seguintes critérios: episódios envolvendo palavras dissílabas, sendo a sílaba inicial com estrutura CVC, envolvendo as letras $\mathrm{R}$ (rótica), $\mathrm{S}$ (fricativa) e a letra $\mathrm{N}$ para marcar a nasalidade.

É importante salientar que a elaboração de categorias é uma tarefa complexa e não pode ser considerada uma "camisa de força"; os tipos de scaffolding podem variar dependendo das situações de interação, dos objetivos da pesquisa/mediação, da idade e do 
temperamento das crianças. Desse modo, na tabela VI apresentamos as categorias utilizadas, sua definição e alguns exemplos.

TABELA 6. Tipos de scaffolding e exemplificação

\begin{tabular}{|c|c|c|c|}
\hline Categorias & Subcategorias & Definição & Exemplo \\
\hline 1.GESTÃO & $\begin{array}{l}\text { 1. De participação e } \\
\text { colaboração }\end{array}$ & $\begin{array}{l}\text { Solicitação de } \\
\text { participação de um } \\
\text { dos integrantes do } \\
\text { grupo, visando a seu } \\
\text { envolvimento com } \\
\text { a tarefa (chamada } \\
\text { nominal da criança, } \\
\text { considerando } \\
\text { que ela estava } \\
\text { dispersa ou por } \\
\text { demonstrar dúvida). } \\
\text { Direcionamento } \\
\text { para realizar uma } \\
\text { tarefa: quem vai ler, } \\
\text { quem vai escrever, } \\
\text { quem vai falar. }\end{array}$ & $\begin{array}{l}\text { “Deixa a Marina } \\
\text { ler.” } \\
\text { “Passa para o } \\
\text { Fernando." } \\
\text { “Camila, presta } \\
\text { atenção.” }\end{array}$ \\
\hline 2. INSTRUC̣ÃO & 2. Operação & $\begin{array}{l}\text { Orientações que } \\
\text { visam a indicar } \\
\text { explicitamente os } \\
\text { procedimentos a } \\
\text { serem seguidos } \\
\text { pelas crianças para } \\
\text { a realização da } \\
\text { tarefa. }\end{array}$ & $\begin{array}{l}\text { "Agora vocês ditam } \\
\text { pra mim." } \\
\text { "Vamos escrever } \\
\text { CORDA." } \\
\text { "Espera aí, vamos } \\
\text { por partes." } \\
\text { "Vou mostrar a } \\
\text { escrita de crianças } \\
\text { de um outro } \\
\text { grupo, pra vocês } \\
\text { me falarem o que } \\
\text { acham." } \\
\text { "Vamos escrever } \\
\text { novamente." }\end{array}$ \\
\hline
\end{tabular}




\begin{tabular}{|c|c|c|c|}
\hline \multirow[t]{3}{*}{ 3. INDAGAC̣ÃO } & 3.1 Inferência & $\begin{array}{l}\text { Pergunta } \\
\text { elaborada a partir } \\
\text { de uma reflexão } \\
\text { metalinguística, que } \\
\text { facilita a inferência. }\end{array}$ & $\begin{array}{l}\text { “Então pra gente } \\
\text { escrever SUSTO } \\
\text { [entonação na letra } \\
\text { S] a gente tem que } \\
\text { pôr qual letra no } \\
\text { início?" } \\
\text { “Depois do S - U que } \\
\text { vocês formaram SU, } \\
\text { vem qual letra?" } \\
\text { "Quantas letras } \\
\text { para escrever } \\
\text { SUSTO?" } \\
\text { "Oual palavra } \\
\text { que nós estamos } \\
\text { escrevendo?" } \\
\text { “Qual é a primeira } \\
\text { letra que vamos } \\
\text { escrever?" }\end{array}$ \\
\hline & $\begin{array}{l}3.2 \text { Questão/ } \\
\text { Pedido de } \\
\text { confirmação }\end{array}$ & $\begin{array}{l}\text { Perguntas explícitas } \\
\text { visando verificar se } \\
\text { o interlocutor está } \\
\text { de acordo com uma } \\
\text { ideia. }\end{array}$ & $\begin{array}{l}\text { "Vocês concordam } \\
\text { que são quatro } \\
\text { letras?" } \\
\text { "Todo mundo } \\
\text { concorda?" }\end{array}$ \\
\hline & $\begin{array}{l}\text { 3.3 Clarificação } \\
\text { Pedido de } \\
\text { explicação }\end{array}$ & $\begin{array}{l}\text { Solicitação de } \\
\text { esclarecimento de } \\
\text { uma ideia. Pedido de } \\
\text { explicação. }\end{array}$ & $\begin{array}{l}\text { “O que você pensou, } \\
\text { Fernando?" } \\
\text { "Vocês acham que é } \\
\text { com S ou com C?" } \\
\text { “Por que você acha } \\
\text { que tem quatro } \\
\text { letras?" }\end{array}$ \\
\hline \multirow[t]{2}{*}{ 4. SINALIZAC̣̃̃O } & 4.1 Tarefa/ação & $\begin{array}{l}\text { Explicitação } \\
\text { verbal que chama } \\
\text { a atenção das } \\
\text { crianças para } \\
\text { executar uma } \\
\text { ação relacionada à } \\
\text { demanda da tarefa. }\end{array}$ & $\begin{array}{l}\text { "Olha como o outro } \\
\text { grupo escreveu." } \\
\text { "Faz o C para eu } \\
\text { ver." } \\
\text { "Ah, olha a ideia do } \\
\text { Fernando." } \\
\text { "Aponta o dedinho } \\
\text { onde está a sílaba". }\end{array}$ \\
\hline & 4.2 Registro & $\begin{array}{l}\text { Registro por escrito } \\
\text { da palavra ou de } \\
\text { parte da palavra } \\
\text { pelo adulto ou pela } \\
\text { criança. }\end{array}$ & \\
\hline
\end{tabular}




\begin{tabular}{|c|c|c|c|}
\hline 5. ELABORAĈ̣̃O & 5. Pista & $\begin{array}{l}\text { Procedimento de } \\
\text { análise fonológica: } \\
\text { prolongamento de } \\
\text { som para fazer } \\
\text { marcação fonêmica. }\end{array}$ & $\begin{array}{l}\text { "S com U é SU". } \\
\text { Quando a gente } \\
\text { coloca o N ... /n/ } \\
\text { fica EN. } \\
\text { “D - E (soletra)" }\end{array}$ \\
\hline \multirow[t]{2}{*}{ 6. REELABORAC̣ÃO } & 6.1 Correção & $\begin{array}{l}\text { Mudança ou } \\
\text { alteração explícita } \\
\text { de uma ideia } \\
\text { ou resposta } \\
\text { considerada } \\
\text { incorreta. }\end{array}$ & $\begin{array}{l}\text { “Lis-ta! Lista. Não } \\
\text { é listra, não. Listra } \\
\text { é igual da zebra. É } \\
\text { lista." } \\
\text { “Então não é o I”. }\end{array}$ \\
\hline & 6.2 Síntese & $\begin{array}{l}\text { Recapitulação de } \\
\text { ideia(s) expressa(s) } \\
\text { por um interlocutor. }\end{array}$ & $\begin{array}{l}\text { "O Fernando viu } \\
\text { que estava faltando } \\
\text { algum som ali } \\
\text { [mostra o papel com } \\
\text { a escrita de DEITE] } \\
\text { e colocou a letra I." } \\
\text { "O Fernando pensou } \\
\text { no I, e esse grupo } \\
\text { aqui pensou no N. } \\
\text { DEN-DEN." } \\
\text { "A Sônia prefere o } \\
\text { S e a Camila prefere } \\
\text { o C." }\end{array}$ \\
\hline 7. AVALIAC̣̃̃O & 7. Feedback positivo & $\begin{array}{l}\text { Avaliação positiva } \\
\text { do trabalho } \\
\text { realizado pelo grupo. }\end{array}$ & $\begin{array}{l}\text { "Muito bem! Essa } \\
\text { foi de primeira." }\end{array}$ \\
\hline
\end{tabular}

Fonte: Quadro elaborado pelas autoras, adaptado de Alves Martins, et. al (2017) e Salvador (2017).

Como pode ser visualizado na tabela VI, os tipos de scaffolding foram organizados de modo a favorecer a análise do processo de interação durante as sessões do Programa de Escrita inventada. Na primeira coluna à esquerda, apresentamos as sete categorias gerais. São elas: gestão, instrução, indagação, sinalização, elaboração, reelaboração e avaliação. E, na segunda coluna, temos as subcategorias de análise, que funcionam como um refinamento das categorias mais gerais.

A primeira categoria é a gestão e a função é gerir a participação das crianças no grupo, de modo a envolvê-las na tarefa e suscitar um trabalho cooperativo. Dispor as carteiras, de modo a promover a interação em grupo, mostrar o livro e as imagens de onde foram retiradas as palavras, garantir o respeito aos turnos de fala, promover a cooperação entre as crianças foram algumas estratégias trabalhadas no grupo. 
A segunda categoria é a instrução e tem a função de orientar as crianças sobre o que fazer: ouvir uma história, ditar as letras que devem ser escritas, argumentar a letra a colocar, ouvir os argumentos do colega, concordar ou discordar do colega de modo respeitoso, escrever as letras ditadas pelo grupo são alguns exemplos.

A terceira categoria é a indagação, que foi agrupada em 3 subcategorias: inferência, pedido de confirmação e pedido de explicação. Essa categoria é primordial para fazer emergir o pensamento infantil, suas hipóteses e argumentos para sustentar uma ideia. É a partir do ato de inquirir que podemos confirmar hipóteses e colocar conflitos para a criança avançar em suas concepções.

A quarta categoria é a sinalização, com função de explicitar a demanda da tarefa e registrar as respostas das crianças, que foram elaboradas coletivamente. A quinta categoria é a elaboração, que apresenta pistas fonológicas que auxiliam as crianças na percepção de algum som que compõe a palavra.

A sexta categoria diz respeito ao processo de reelaboração, em que a mediadora faz alguma correção ou sintetiza uma ideia. E a sétima e última categoria é a avaliação, com mensagens positivas sobre a atuação do grupo na tarefa.

Essas categorias não foram elaboradas a priori, em primeiro lugar, foram feitas as transcrições de cada episódio, segmentado em mensagens de interação verbalizadas pela mediadora da pesquisa. $\mathrm{O}$ processo de enquadramento das interações verbais nas categorias, apresentadas no parágrafo anterior, não foi uma tarefa fácil e exigiu uma ação de comparação permanente, de modo que é bem comum a modificação, diversificação ou junção de categorias ao longo do processo de análise.

A proposta aqui não é apresentar estratégias pré-definidas, mas revelar estratégias e modelos de conduta que podem ser usados na mediação com crianças de forma a contribuir para alavancar suas aprendizagens. É importante observar que a assistência ou scaffolding que o adulto fornece à criança em um determinado momento, em outro momento pode ser retirada, à medida que a criança começa a trabalhar de maneira independente. A seguir, apresentaremos os tipos de scaffolding usados na pesquisa. Cabe analisar, também, quando emergem tais intervenções e a frequência com que desaparecem. $\mathrm{Na}$ tabela VII, apresentaremos os tipos de scaffolding e sua recorrência nas três sessões analisadas. 
TABELA 7. Tipo de scaffolding por sessão

\begin{tabular}{|c|c|c|c|c|c|c|}
\hline \multicolumn{2}{|c|}{ Tipos de Scaffolding } & \multicolumn{3}{|c|}{ Sessões } & \multirow[b]{2}{*}{$\mathrm{F}$} & \multirow[b]{2}{*}{$\%$} \\
\hline Categorias & Subcategorias & S1 & S2 & S3 & & \\
\hline 1. Gestão & Participação & 5 & 11 & 7 & 23 & 11,0 \\
\hline 2. Instrução & Operação & 6 & 9 & 6 & 21 & 10,0 \\
\hline \multirow[t]{3}{*}{ 3. Indagação } & Inferência & 18 & 13 & 10 & 41 & 19,6 \\
\hline & Confirmação & 16 & 9 & 9 & 34 & 16,3 \\
\hline & Explicação & 6 & 7 & 3 & 16 & 7,7 \\
\hline \multirow[t]{2}{*}{ 4. Sinalização } & Tarefa/ação & 8 & 9 & 1 & 18 & 8,6 \\
\hline & Registro & 7 & 12 & 0 & 19 & 9,1 \\
\hline 5. Elaboração & Pista & 4 & 9 & 8 & 21 & 10,0 \\
\hline \multirow[t]{2}{*}{ 6. Reelaboração } & Correção & 1 & 1 & 0 & 2 & 1,0 \\
\hline & Síntese & 7 & 0 & 3 & 10 & 4,8 \\
\hline 7. Avaliação & Feedback positivo & 0 & 2 & 2 & 4 & 1,9 \\
\hline \multicolumn{2}{|c|}{ TOTAL } & 78 & 82 & 49 & 209 & 100 \\
\hline
\end{tabular}

Fonte: Elaborado pelas autoras com os dados da pesquisa.

GRÁFICO 2. Porcentagem dos tipos de scaffolding usados na mediação no conjunto das 3 sessões

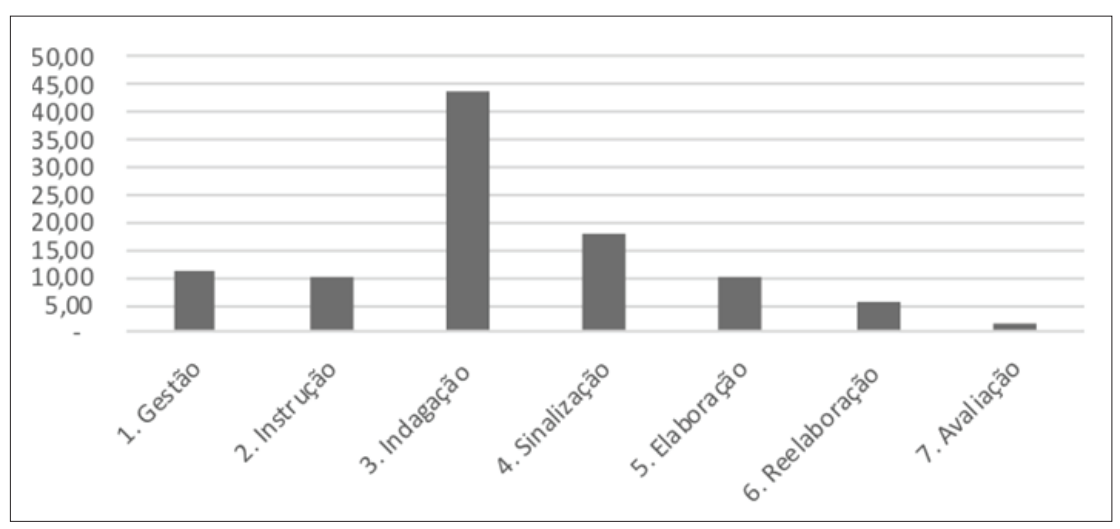

Fonte: Elaborado pelas autoras com os dados da pesquisa. 
GRÁFICO 3. - Porcentagem das subcategorias dos tipos de scaffolding usados na mediação no conjunto das 3 sessões (subcategorias)

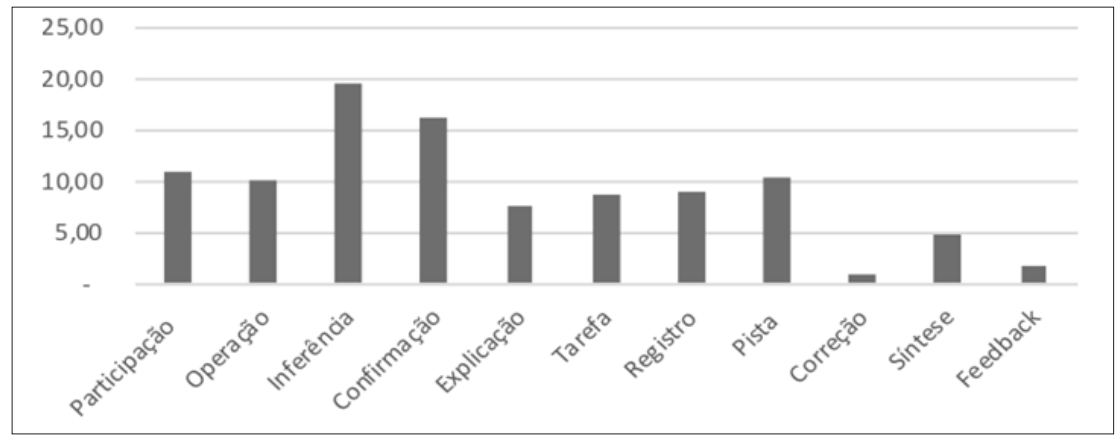

Fonte: Elaborado pelas autoras com os dados da pesquisa.

A partir da análise dos gráficos II e III, podemos visualizar melhor as categorias e as subcategorias e perceber quais tipos de scaffolding foram priorizados no decorrer das 3 sessões, subdivididos em 9 episódios do Programa de Escrita Inventada. No gráfico II, podemos visualizar o predomínio das interações verbais interrogativas (43,6\%), envolvendo questões de inferência, confirmação e explicação, como pode ser verificado no gráfico III. Dessas, quase a metade das questões visavam a facilitar a elaboração de inferências pelas crianças $(19,6 \%)$, ou seja, questões que as auxiliavam a pensar sobre os sons envolvidos na escrita da palavra, como, por exemplo: "Então pra gente escrever SUSTO [entonação na letra S], a gente tem que pôr qual letra no início?" $16,3 \%$ das questões foram direcionadas para verificar se as crianças estavam de acordo ou não com uma proposição elaborada por um dos integrantes do grupo e $7,7 \%$ para justificar uma ideia, como, por exemplo: "Por que você acha que tem quatro letras?".

Também há um volume significativo de interações verbais voltadas para a sinalização, num total de $17,7 \%$, com $8,6 \%$ das mensagens dirigidas para que a criança realizasse alguma ação voltada para a execução da tarefa, como, por exemplo, ação de comparação: "Olha como o outro grupo escreveu." "Olha se está faltando alguma coisa." Ou para demonstrar um conhecimento: "Aponta com o dedinho", "Marca onde que está a sílaba LIS". Ainda na categoria sinalização, 9,1\% das mensagens estavam relacionadas ao registro da palavra no papel, conforme elaboração do grupo. Observase, nos últimos episódios da Sessão 3, que essa ação não era mais executada pela mediadora, pois quem fazia o registro das palavras eram as próprias crianças, por isso essa categoria encontra-se zerada. Após o registro da palavra elaborado pelo grupo, era solicitado às 
crianças que comparassem seu registro com a escrita hipotética de outras crianças (escrita convencional), a partir da seguinte mensagem: "Olha como outro grupo escreveu", favorecendo, assim, a reflexão metalinguística acerca da escrita da palavra. Nesta linha de pensamento, as interações verbais centradas na análise oral da palavra, nomeadas de "Elaboração", que totalizaram 10\%, consistiam em fornecer pistas fonológicas para as crianças, "S com U é SU" com prolongamento do som /s/, "Vamos escrever LIN-DA (prolongamento do som /n/ e repartição das sílabas). Esse tipo de mensagem, que consiste em fornecer uma resposta precisa, foi usada para confirmar uma análise metalinguística feita por uma das crianças que apresentava hipóteses mais avançadas. Sabemos que a informação disponibilizada pode ou não gerar conflitos ou consolidação de habilidades para as crianças que estavam em hipóteses iniciais da construção do sistema de escrita alfabética. Exemplo disso é o resultado do pós-teste de Fernando, que conseguiu avançar no processo de construção da escrita, em contraste com menor avanço de Camila.

As interações verbais voltadas para a gestão do grupo (11\%) e instruções operacionais $(10 \%)$ foram importantes no sentido de esclarecer para as crianças as regras de funcionamento do grupo e regular seus comportamentos, de modo a garantir a participação colaborativa. Com relação às demais categorias, apenas 5,8\% das interações verbais foram destinadas para corrigir ou sintetizar uma ideia.

Observou-se que os episódios de cada uma das sessões iniciavam com interações verbais de sinalização, com a leitura de um gênero textual extraído de livros de literatura infantil de autoria de Eva Furnari e Ana Maria Machado, que davam o mote para a escrita das palavras. Essas interações garantiam a atenção das crianças, que se voltavam para a mediadora, e também a motivação para desenvolver a tarefa, quando compreendiam o sentido e o significado da palavra, conforme a Imagem I. 
IMAGEM I. Leitura do livro "Bruxinha Zuzu", de Eva Furnari, para contextualização da escrita da palavra SUSTO.

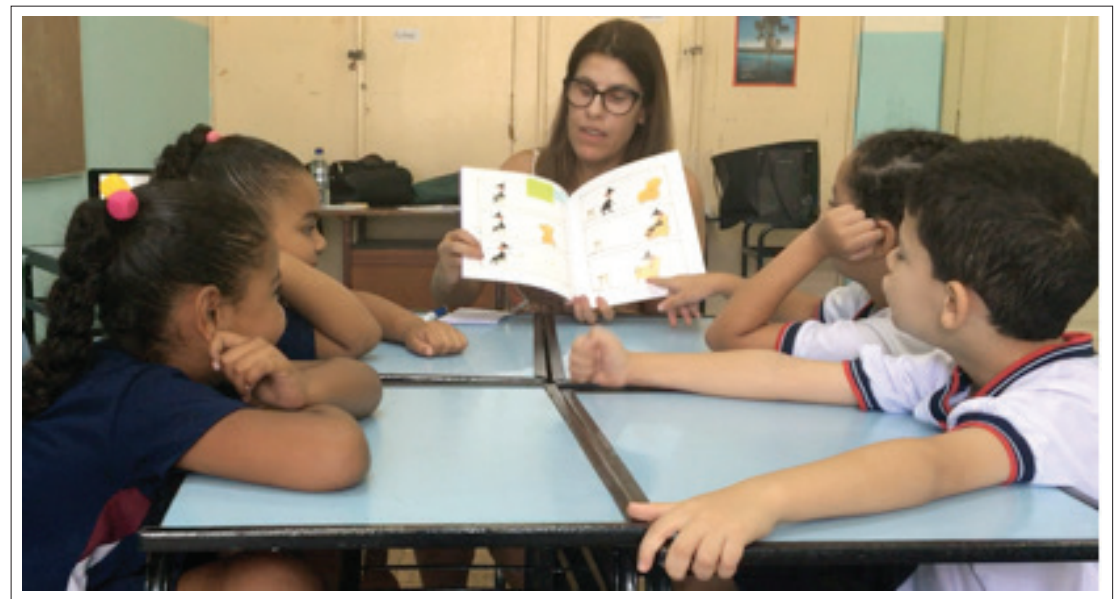

Fonte: Arquivo da pesquisadora (Sessão I - Programa Escrita Inventada, 03/04/2018).

Em seguida à leitura do gênero textual, a mediadora fornecia uma instrução operacional: "Vamos escrever CORDA", por exemplo. Como exposto anteriormente, as mediações que visavam dar instrução operacional foram bem escassas $(10 \%)$ e, geralmente, eram fornecidas no início das sessões. Conclui-se que prevalecem as interações verbais que visavam inquirir as crianças sobre suas hipóteses de escrita, tendo como base a análise metalinguística (43,6\%). Isso significa que o tipo de interação que buscamos estabelecer no Programa de Escrita Inventada está em consonância com as bases teóricas de Vygostsky e da escola histórico-cultural e se apoia em estratégias argumentativas.

Outra análise importante diz respeito à frequência das interações no decorrer das sessões. O gráfico IV compara o volume de mensagens de intervenção destinado a cada sessão: inicial, intermediária e final, e permite visualizar um ligeiro aumento das mensagens de intervenção da sessão inicial para a intermediária e uma diminuição significativa da sessão intermediária para a final. 
GRÁFICO 4. Frequência de intervenção na sessão inicial, intermediária e final

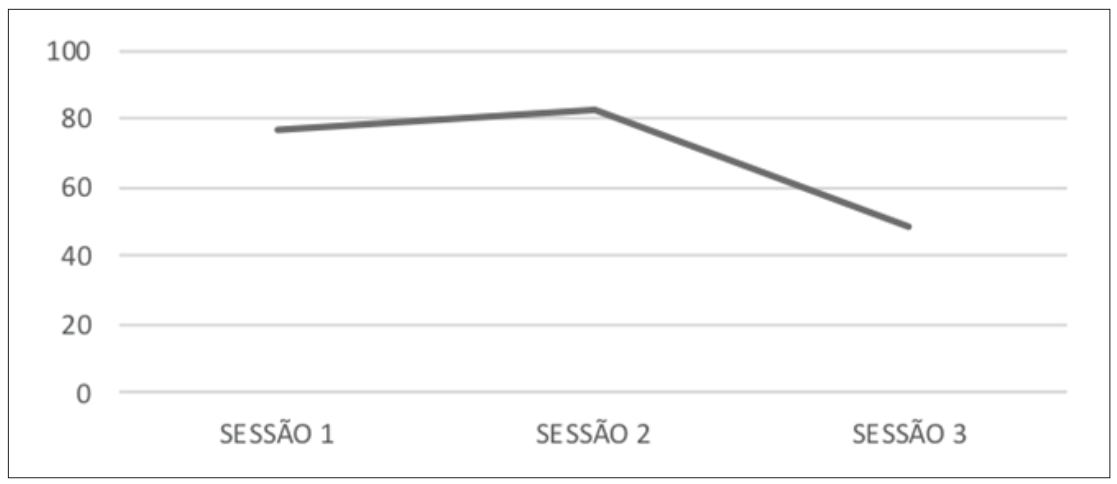

Fonte: Elaborado pelas autoras com os dados da pesquisa.

A justificativa do ligeiro aumento das interações verbais da sessão 1 para a sessão 2 está relacionada à introdução de uma instrução nova a partir da sessão 2 , a leitura da escrita final da palavra por cada integrante do grupo, mostrando cada sílaba lida. Esse tipo de scaffolding foi introduzido com o objetivo de verificar a leitura individual da criança da palavra produzida coletivamente. Da sessão 2 para a sessão 3 , há uma queda de $40 \%$ das mensagens de interação verbal, corroborando a ideia de que os scaffolding são retirados à medida que as crianças adquirem autonomia na escrita da palavra (PONTECORVO, 2005).

$\mathrm{Na}$ presente pesquisa, a habilidade em foco é a aquisição do sistema de escrita alfabética, mais precisamente, levar as crianças a compreenderem que as sílabas podem apresentar outras estruturas além da CV; no caso das palavras selecionadas para discussão neste artigo, são as composições silábicas CVC e CV[nasal]. No próximo tópico, vamos apresentar as mediações efetuadas no Programa de Escrita Inventada de palavras com essas estruturas silábicas.

\section{AS MEDIAÇ̃̃ES NA ESCRITA INVENTADA COLABORATIVA DE PALAVRAS CVC E CV[NASAL]}

A partir da análise da tabela VIII, podemos acompanhar as escritas colaborativas das crianças, no decorrer das três sessões: inicial, intermediária e final. 
TABELA 8. Escritas colaborativas produzidas em 3 sessões

\begin{tabular}{|c|c|c|c|c|c|}
\hline Palavra & Sessão & Episódio & $\begin{array}{c}\text { Escritas } \\
\text { colaborativas }\end{array}$ & $\begin{array}{l}\text { Produção final } \\
\text { após confronto }\end{array}$ & Acertos \\
\hline SUSTO & 1 & 1 & SUTO & SUTO & 4 \\
\hline CORDA & 1 & 2 & $\begin{array}{c}\text { CODA } \\
\text { COUDA } \\
\text { CORDA }\end{array}$ & $\begin{array}{l}\text { Não houve } \\
\text { confronto. }\end{array}$ & 5 \\
\hline DENTE & 1 & 3 & $\begin{array}{c}\text { DETI } \\
\text { DEITI } \\
\text { DEITE }\end{array}$ & DENTE & 5 \\
\hline LISTA & 2 & 4 & $\begin{array}{l}\text { LIPA } \\
\text { LITA } \\
\text { LISTA }\end{array}$ & $\begin{array}{l}\text { Não houve } \\
\text { confronto. }\end{array}$ & 5 \\
\hline CARNE & 2 & 5 & CARNE & $\begin{array}{l}\text { Não houve } \\
\text { confronto. }\end{array}$ & 5 \\
\hline LINDA & 2 & 6 & $\begin{array}{l}\text { LIDA } \\
\text { LINDA }\end{array}$ & $\begin{array}{l}\text { Não houve } \\
\text { confronto. }\end{array}$ & 5 \\
\hline SURDO & 3 & 7 & SURDO & $\begin{array}{l}\text { Não houve } \\
\text { confronto. }\end{array}$ & 5 \\
\hline GOSTO & 3 & 8 & GOSTO & $\begin{array}{l}\text { Não houve } \\
\text { confronto. }\end{array}$ & 5 \\
\hline VENTO & 3 & 9 & $\begin{array}{c}\text { VETO } \\
\text { VENTO }\end{array}$ & $\begin{array}{l}\text { Não houve } \\
\text { confronto. }\end{array}$ & 5 \\
\hline Total 45 & & & & & 44 \\
\hline
\end{tabular}

Fonte: Elaborado pelas autoras.

Ressalta-se que a única palavra em que a escrita final não correspondeu à escrita convencional foi a palavra SUSTO. É importante ressaltar que essa palavra foi uma das primeiras produzidas pelo grupo; além disso, na escrita dessa palavra, sobressaiu a hipótese de que, para escrever palavras dissílabas, precisamos de quatro letras, como se todas as palavras fossem formadas por sílabas canônicas CV. Essa hipótese foi levantada inicialmente por Fernando (Imagem II) e defendida por Camila no final do episódio. A seguir, transcrevemos o excerto do início do episódio, que elucida as interações verbais estabelecidas entre a mediadora e a criança. Também apresentamos os tipos de scaffolding: 
1. Mediadora Essa que é a palavra que a gente vai instrução/operação
escrever: SUSTO.

2. Fernando Su... Su... Su (faz um biquinho e realiza contagem usando os dedos).

3. Mediadora O que você pensou, Fernando? indagação/explicação

4. Mediadora Quantas letras? indagação/inferência

5. Fernando Quatro. $\begin{array}{lll}\text { 6. Mediadora } & \text { Todo mundo acha que tem quatro } & \text { indagação/confirma- } \\ \text { letras? } & \text { ção }\end{array}$

IMAGEM 2. Fernando conta com os dedos o número de letras para a escrita da palavra SUSTO.

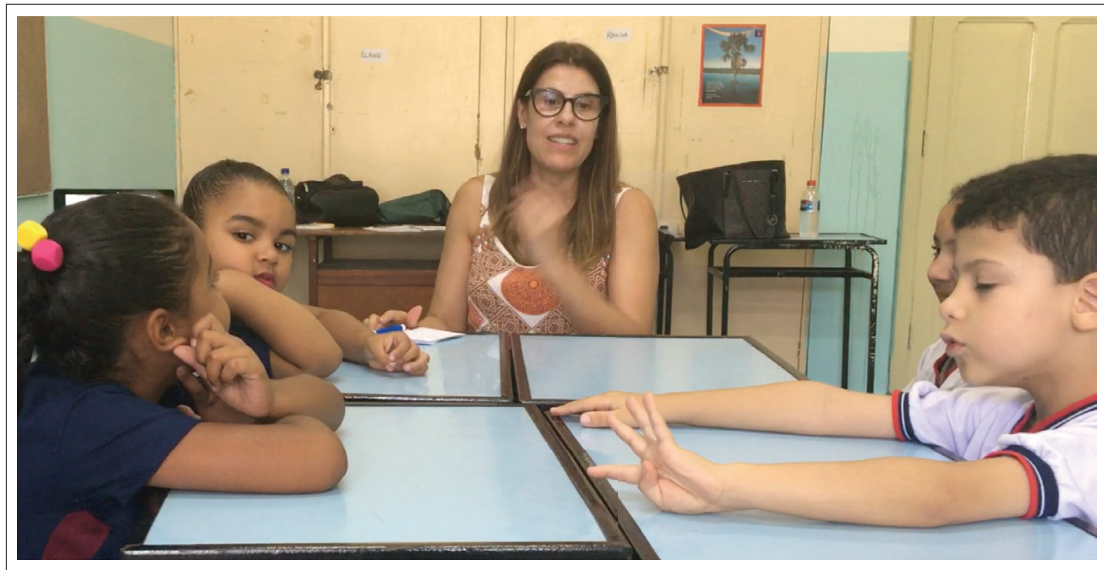

Fonte: Arquivo da pesquisadora (Sessão I - Programa de Escrita Inventada, 03/04/2018).

Na sequência do episódio, todas as crianças concordaram que, para escrever a palavra SUSTO, era preciso colocar quatro letras, e produziram a escrita SUTO. O excerto do episódio, a seguir, mostra que Sônia e Marina não concordaram com a escrita SUTO e levantaram algumas hipóteses. Uma apontou que faltava a letra 'S' e a outra, que faltava a letra 'I', respectivamente. 


\section{Sônia Faltou o S}

2. Marina Eu acho que faltou o I.

\begin{tabular}{lll} 
3. Mediadora & $\begin{array}{l}\text { Tem gente que acha que faltou o I, } \\
\text { tem gente que acha que faltou o S. }\end{array}$ & $\begin{array}{l}\text { Reelaboração/ } \\
\text { síntese }\end{array}$ \\
$\begin{array}{lll}\text { 4. Marina } & \text { Não sei. } & \text { Indagação/ } \\
\text { inferência }\end{array}$ \\
\hline 5. Mediadora & Está faltando alguma letra? &
\end{tabular}
6. Fernando
Normal.

$\begin{array}{ll}\text { 7. Mediadora } & \text { Normal? } \\ & \begin{array}{l}\text { Indagação/ex- } \\ \text { plicação }\end{array}\end{array}$

8. Marina

Tá faltando um I, aqui. [Aponta o dedo entre as letras $\mathrm{U}$ e $\mathrm{T}]$

$\begin{array}{lll}\text { 9. Mediadora } & \text { Se a gente colocar o I }(\ldots) & \text { Indagação/ } \\ \text { inferência }\end{array}$

10. Sônia Vai ficar SUISTO.

11. Sônica e Camila SUSTO. [Repetem a palavra]

\begin{tabular}{|c|c|c|}
\hline 12. Mediadora & É o I, gente? & $\begin{array}{l}\text { Indagação/ } \\
\text { confirmação }\end{array}$ \\
\hline 13. Sônia e Camila & $\begin{array}{l}\text { Não. [Fernando e Marina não re- } \\
\text { spondem]. }\end{array}$ & \\
\hline 14. Sônia & $\begin{array}{l}\text { É um S. SUS -TO [Fala a palavra } \\
\text { marcando pausadamente as sílabas] }\end{array}$ & \\
\hline 15. Mediadora & Tem mais um S? & $\begin{array}{l}\text { Indagação/ } \\
\text { inferência }\end{array}$ \\
\hline 16. Camila & $\begin{array}{l}\text { [Balança a cabeça indicando que } \\
\text { não]. }\end{array}$ & \\
\hline 17. Sônia & Não sei. & \\
\hline
\end{tabular}

Observa-se que Sônia e Marina discordaram inicialmente da escrita produzida pelo grupo. Entretanto, Sônia desconstruiu a hipótese de Marina de inserir a letra ' $I$ ' e fez a leitura enfatizando o som /i/, mostrando o erro da colega (linha 10). Apesar de falar pausadamente a palavra, enfatizando as sílabas SUS-TO no sentido de demonstrar que estava faltando a letra $S$, diante da pergunta 
da mediadora, "Tem mais um S"? (linha 15), Sônia demonstra sua dúvida: "Não sei” (linha 17). Neste episódio, a indagação da mediadora pode não ter sido a mais adequada e ter desencadeado um conflito relacionado à hipótese, que muitas crianças possuem no processo de apropriação da escrita alfabética, de não ser permitido repetir letras dentro de uma mesma palavra, conforme estudos de Ferreiro e Teberosky (1985).

Por fim, Sônia concordou com a escrita final SUTO, diante do argumento de Camila "Todo mundo falou que era quatro letras. Era só quatro letras." Sônia e Marina contaram as letras da palavra SUTO e concordaram com a escrita. Neste episódio, Fernando e Camila tinham certeza da escrita produzida, Sônia e Marina não construíram argumentos sólidos para alterar a escrita do grupo, e o critério que prevaleceu foi o de que, para cada sílaba, colocamos duas letras, dentro da lógica da canonicidade silábica, e também a hipótese de não ser permitido repetir letras dentro de uma mesma palavra (FERREIRO \& TEBEROSKY, 1985).

Ao retomar o quadro VIII, notamos que o mesmo não acontece com a escrita das palavras LISTA e GOSTO, palavras em que não há repetição de consoantes. A seguir, apresentamos excerto da escrita colaborativa da palavra LISTA.

\begin{tabular}{|c|c|c|}
\hline 1. Mediadora & $\begin{array}{l}\text { O menino da história criou um clube. } \\
\text { O clube dele era de quê, gente? }\end{array}$ & $\begin{array}{l}\text { Sinalização/ } \\
\text { tarefa }\end{array}$ \\
\hline 2. Sônia & De ideias. & \\
\hline 3. Fernando & Listra! & \\
\hline 4. Mediadora & $\begin{array}{l}\text { Lis-ta! Lista. Não é listra, não. Listra é } \\
\text { igual da zebra. É lista. }\end{array}$ & $\begin{array}{l}\text { Reelaboração/ } \\
\text { correção }\end{array}$ \\
\hline 5. Sônia & Lis-ta [fala junto com a mediadora] & \\
\hline 6. Mediadora & Vamos escrever a palavra LIS-TA! & $\begin{array}{l}\text { Instrução/op- } \\
\text { eração }\end{array}$ \\
\hline 7. Fernando & LI - LI [repete a sílaba] & \\
\hline $\begin{array}{l}\text { 8. Camila, Fernando e } \\
\text { Marina }\end{array}$ & L - I [soletram juntos] & \\
\hline 9. Mediadora & É, Sônia? & $\begin{array}{l}\text { Indagação/con- } \\
\text { firmação }\end{array}$ \\
\hline 10. Sônia & L - I [soletra] & \\
\hline
\end{tabular}




\begin{tabular}{|c|c|c|}
\hline 11. Mediadora & L - I [soletra] & $\begin{array}{l}\text { Reelaboração/ } \\
\text { síntese }\end{array}$ \\
\hline 12. Sônia & T-A & \\
\hline 13. Fernando & L - I - T [soletra] & \\
\hline 14. Sônia & $\begin{array}{l}\text { Espera aí! LIS [sílaba], agora é o S. } \\
\text { Não é o T. }\end{array}$ & \\
\hline 15. Camila & T e A. & \\
\hline 16. Mediadora & [Faz o registro LITA] & $\begin{array}{l}\text { Sinalização/ } \\
\text { registro }\end{array}$ \\
\hline 17. Marina & $\begin{array}{l}\text { LIS [pronuncia a sílaba], antes do T } \\
\text { era o S. }\end{array}$ & \\
\hline 18. Mediadora & Então, vamos escrever novamente. & $\begin{array}{l}\text { Instrução/op- } \\
\text { eração }\end{array}$ \\
\hline $\begin{array}{l}\text { 19. Sônia, Marina e } \\
\text { Fernando }\end{array}$ & L-I [letras] & \\
\hline 20. Mediadora & [Faz o registro LI] & $\begin{array}{l}\text { Sinalização/ } \\
\text { registro }\end{array}$ \\
\hline 21. Mediadora & Concorda, Camila? & $\begin{array}{l}\text { Gestão/partici- } \\
\text { pação }\end{array}$ \\
\hline 22. Camila & [Acena com a cabeça, concordando] & \\
\hline 23. Mediadora & Todos concordam? & $\begin{array}{l}\text { Indagação/con- } \\
\text { firmação }\end{array}$ \\
\hline 24. Sônia & S. & \\
\hline 25. Mediadora & LIS [enfatiza o som do /s/ na sílaba] & $\begin{array}{l}\text { Elaboração/ } \\
\text { pista }\end{array}$ \\
\hline 26. Fernando & LIS - É o S, S, S [enfatiza a letra] & \\
\hline 27. Mediadora & [Registra o S formando a sílaba LIS] & $\begin{array}{l}\text { Sinalização/ } \\
\text { registro }\end{array}$ \\
\hline 28. Mediadora & E agora, depois do LIS? & $\begin{array}{l}\text { Indagação/in- } \\
\text { ferência }\end{array}$ \\
\hline 29. Sônia & T - A [soletra] & \\
\hline 30. Fernando e Marina & T - A [soletram ao mesmo tempo] & \\
\hline 31. Sônia & LIS-TA & \\
\hline 32. Mediadora & $\begin{array}{l}\text { [Registra a sílaba TA e escreve a pala- } \\
\text { vra LISTA] }\end{array}$ & $\begin{array}{l}\text { Sinalização/ } \\
\text { registro }\end{array}$ \\
\hline
\end{tabular}


Nesse episódio da sessão intermediária, nota-se que foram utilizados vários tipos de scaffolding, iniciando com a sinalização e correção da palavra que seria produzida (linhas 1 e 4); seguida de indagações com pedido de confirmação, uma vez que as crianças participaram intensamente e apresentavam suas hipóteses quase que simultaneamente. Nota-se que Sônia, Fernando e Camila (linhas 12, 13 e 15, respectivamente) ainda trabalhavam com a hipótese do padrão CV. A interação verbal da mediadora no sentido de fornecer uma pista fonológica (linha 25) foi importante para que Fernando percebesse a necessidade de inserir a letra $S$ na palavra, "LIS, é o S, S, S" (linha 26). Nota-se que Sônia e Marina já haviam sinalizado anteriormente essa análise fonológica: "Espera aí! LIS, agora é o S, não é o T", diz Sônia (linha 14), "LIS, antes do T era o S", diz Marina (linha 17). Parece que Camila concordou com a escrita sem muita convicção e foi preciso que a mediadora convocasse sua participação (linha 21). É importante salientar que, ao analisar o resultado do pósteste, todas as crianças, exceto Camila, produziram corretamente a escrita da palavra COSTA. A escrita individual de Camila no pósteste e pós-teste postergado mostra ainda a prevalência do padrão de escrita CV e escreveu COTA.

Vamos passar para o excerto da última sessão envolvendo a letra S, som da fricativa /s/ em posição final de sílaba.

\begin{tabular}{|c|c|c|}
\hline 1.Mediadora & Vamos escrever a palavra GOSTO? & $\begin{array}{l}\text { Instrução/ } \\
\text { operação }\end{array}$ \\
\hline 2. Mediadora & A Sônia vai escrever. & $\begin{array}{l}\text { Gestão/par- } \\
\text { ticipação }\end{array}$ \\
\hline 3. Mediadora & Sônia, qual letra que começa? & $\begin{array}{l}\text { Indagação/ } \\
\text { inferência }\end{array}$ \\
\hline 4. Sônia & G & \\
\hline 5. Marina & $\mathrm{G}-\mathrm{O}$ [soletra as letras] & \\
\hline 6. Mediadora & $\mathrm{G}-\mathrm{O}$ & $\begin{array}{l}\text { Reelaboração/ } \\
\text { síntese }\end{array}$ \\
\hline 7. Mediadora & Todo mundo concorda? & $\begin{array}{l}\text { Indagação/ } \\
\text { confirmação }\end{array}$ \\
\hline 8. Crianças & $\begin{array}{l}\text { [balançam a cabeça afirmando que } \\
\text { sim e Fernando faz o movimento da } \\
\text { letra G na carteira] }\end{array}$ & \\
\hline
\end{tabular}


9. Sônia [Faz o registro das letras GO]

10. Sônia Agora o S.

$\begin{array}{ll}\text { 11. Mediadora } \quad \text { Tem S? } & \begin{array}{l}\text { Indagação/ } \\ \text { inferência }\end{array}\end{array}$

12. Marina, Fernan- GOS [Repetem a sílaba com ênfase

do e Camila no som /s/]

13. Fernando GOSSS [enfatiza o som /s/]

\begin{tabular}{|c|c|c|}
\hline 14. Mediadora & Se eu não colocar o S como que fica? & $\begin{array}{l}\text { Indagação/ } \\
\text { inferência }\end{array}$ \\
\hline 15. Crianças & GO-TO & \\
\hline 16. Mediadora & $\begin{array}{l}\text { Então precisa do S na sílaba GOS } \\
\text { para fazer esse som /s / - GOS-TO }\end{array}$ & $\begin{array}{l}\text { Reelaboração/ } \\
\text { síntese }\end{array}$ \\
\hline 17. Sônia & $\begin{array}{l}\text { [Registra a letra } \mathrm{S} \text { e forma a sílaba } \\
\text { GOS] }\end{array}$ & \\
\hline 18. Sonia & Agora T -O [soletra] & \\
\hline 19. Mediadora & Concordam que é T-O? & $\begin{array}{l}\text { Indagação/ } \\
\text { confirmação }\end{array}$ \\
\hline 20. Crianças & Sim! & \\
\hline
\end{tabular}

Nesse episódio da última sessão, fica evidente que as crianças compreenderam que a palavra é formada por uma cadeia sonora que, por sua vez, é segmentada em unidades menores (fonemas). Com relação à estrutura silábica CVC, a mediadora lança um desafio para as crianças ao indagar "Se eu não colocar o S como que fica?" (linha 14) e as crianças, mesmo sem o apoio da escrita, conseguiram inferir que a escrita ficaria errada GOTO e não GOSTO. Esse episódio nos revela que, ao compararmos com a primeira sessão, em que havia mais dúvidas do que habilidades consolidadas, e mesmo com o apoio da escrita e do confronto, as crianças optaram pela escrita dentro do padrão CV. Na sessão intermediária, a estratégia da mediadora foi recorrer ao confronto das escritas colaborativas, além de lançar mão de pistas fonológicas.

Na última sessão, mesmo sem apoio da escrita, as crianças já conseguiam perceber que faltava uma letra, evidenciando um grau de autonomia na execução da tarefa e desenvolvimento da capacidade de identificação de todos os fonemas que compõem a palavra. Camila 
também apresenta um bom desempenho na tarefa; podemos afirmar que as interações atuavam na Zona de Desenvolvimento Proximal (Vygotsky, 2001), ou seja:

aquela área de funcionamento psicológico em que é possível para o sujeito realizar algo, desde que conte com o auxílio de outra pessoa e, portanto, com uma forma de interação e de regulação que sustenta e ativa as funções que ainda não operam sozinhas, mas que necessitam do auxílio externo. (PONTECORVO, 2005, p.25).

Retomando novamente a tabela VIII, observamos que, já na primeira sessão, as crianças identificaram o som da letra $\mathrm{R}$ (rótico) na escrita da palavra CORDA e não houve a necessidade do confronto com a escrita convencional. Também as palavras produzidas nas sessões intermediária e final, CARNE e SURDO, respectivamente, foram produzidas sem apoio do confronto. A estratégia principal utilizada pela mediadora foi a da leitura da palavra produzida pelo grupo, que rapidamente identificava a ausência do grafema $\mathrm{R}$ para representar o som $/ \mathrm{r} /$.

Após a escrita de $C O D A$ e diante da intervenção da mediadora que solicitou que fizessem a leitura da palavra, as crianças chegaram à conclusão de que estava errada. Segue excerto das interações:

1. Marina Não tá certo [Refere-se à escrita

produzida pelo grupo CODA].

2. Mediadora Não? Tá faltando qual letra? Indagação/ inferência

3. Marina Faltou o U.

4. Sônia COUDA? 5. Camila e Fer- CORDA [Repetem a palavra].
nando

6. Mediadora É corda. Sinalização/ tarefa

7. Sônia e Marina O R. [Falam ao mesmo tempo]

8. Fernando O barulho que faz [emite o som /r/].

É o R.

9. Mediadora

Você concorda que a letra que faz esse Indagação/ som /r/ é o R? [Volta-se para a Camila]. confirmação 
10. Camila [Coloca as mãos no rosto e não respon-

de, parece insegura.]

Tá parecendo o ronco da Peppa. [Peppa

11. Sônia Pig é um porco, personagem de um

desenho animado]

12. Marina COR. [enfatiza o som R]

$\begin{array}{lll}\text { 13. Mediadora } & \text { Então, pra fazer esse som é qual letra? } & \text { Reelaboração/ } \\ & \text { O Fernando acha que é o R. } & \text { síntese }\end{array}$

14. Mariana Eu também.

15. Sônia Eu também acho que é o R.

16. Camila Eu também.

17. Mediadora Tem certeza? [direciona para Camila]? $\quad \begin{aligned} & \text { Indagação/ } \\ & \text { confirmação }\end{aligned}$

18. Camila [Balança a cabeça afirmando que sim]

19. Mediadora Então tem que pôr aonde o R? $\quad \begin{aligned} & \text { Indagação/ } \\ & \text { inferência }\end{aligned}$

20. Crianças Aqui. [Todas apontam o dedo entre as

letras $\mathrm{O}$ e D]

21. Fernando No meio.

22. Mediadora Todo mundo concorda? indagação/

23. Crianças Sim.

Corroborando estudos que mostram a facilidade que as crianças demonstram para grafar a letra $\mathrm{R}$ nas sílabas CVC, provavelmente a pronúncia do fonema rótico representado pela letra $\mathrm{R}$ é mais bem percebida por sua posição pós-vocálica (SOARES, 2016).

Ao comparar o volume de interações verbais estabelecidas na sessão 1, nota-se que o volume de interações para a palavra CORDA (17) é bem menor do que para a escrita das outras palavras: SUSTO (33) e DENTE (28).

Com relação à sílaba CV[nasal], sendo a consoante nasal 
pós-vocálica marcada pela letra 'N' como em DENTE, LINDA e VENTO, notamos também a presença de um volume maior de interações verbais que apresentassem pistas fonológicas. As crianças só percebem que falta a letra $\mathrm{N}$ depois do registro escrito e a leitura da palavra DETE, LIDA ou VETO. Também é possível verificar no resultado pós-teste que Marina e Camila escreveram PETE para PENTE, mostrando as dificuldades na marcação da nasalidade. Para exemplificar o que foi dito, apresentaremos o excerto da escrita colaborativa da palavra LINDA.

\begin{tabular}{|c|c|c|}
\hline 1. Mediadora & Leia, olha aqui, veja se está certo. & $\begin{array}{l}\text { Sinalização/ } \\
\text { tarefa }\end{array}$ \\
\hline $\begin{array}{l}\text { 2. Marina, Fernando } \\
\text { e Sônia }\end{array}$ & LI-DA & \\
\hline 3. Mediadora & É LIDA ou LINDA? & $\begin{array}{l}\text { Indagação/expli- } \\
\text { cação }\end{array}$ \\
\hline 4. Crianças & LIN-DA & \\
\hline 5. Mediadora & LIN [nasalização da vogal I] & Elaboração/pista \\
\hline 6. Sônia & É o N. & \\
\hline 7. Fernando & N. & \\
\hline 8. Mediadora & Tem N? Aonde? & $\begin{array}{l}\text { Indagação/expli- } \\
\text { cação }\end{array}$ \\
\hline 9. Fernando & No meio. & \\
\hline 10. Sônia & Aqui, no lugar do D. & \\
\hline 11. Fernando & No meio. & \\
\hline 12. Mediadora & No meio de qual? & $\begin{array}{l}\text { Indagação/expli- } \\
\text { cação }\end{array}$ \\
\hline 13. Sônia & No meio perto do I. & \\
\hline 14. Mediadora & Entre o I e qual outra letra? & $\begin{array}{l}\text { Indagação/in- } \\
\text { ferência }\end{array}$ \\
\hline $\begin{array}{l}\text { 15. Fernando e } \\
\text { Sônia }\end{array}$ & D. & \\
\hline
\end{tabular}


Observa-se que as crianças perceberam a diferença entre as palavras quando foi pronunciada pela mediadora (linha 3). A pista fonológica fornecida com a nasalização da vogal I foi percebida por Sônia e Fernando (linhas 6 e 7). Marina e Camila apenas confirmam a informação na sequência do episódio, mediante a solicitação da mediadora. Nota-se que a estratégia usada pela mediadora foi nasalizar a vogal. Segundo Soares (2016), diferentemente dos fonemas representados pelas letras $\mathrm{R}$ (rótica) e $\mathrm{S}$ (fricativa), em que a pronúncia é perceptível para a criança, no caso dos fonemas representados pelas letras $\mathrm{M}$ e N, essas letras apenas nasalizam a vogal núcleo da sílaba.

Isso explica a alta frequência de erros na escrita de palavras com vogais nasais por crianças em fase de alfabetização e a aprendizagem tardia da escrita de sílabas CV[nasal], quando, ao contrário, estudos sobre o desenvolvimento da linguagem na criança revelam que a aquisição fonológica dessa estrutura CV[nasal] é precoce. (SOARES, 2016, p.319).

\section{CONSIDERACִÕES FINAIS}

Os dados desta pesquisa revelaram que o programa de Escrita Inventada propiciou o avanço nas escritas do grupo investigado, no que se refere ao reconhecimento de estruturas silábicas complexas (CVC) e CV com nasalização de vogais. Após o desenvolvimento das sessões, $75 \%$ das crianças consolidaram habilidades envolvendo a estrutura silábica CVC nas palavras contendo fonemas representados pelas letras R (rótica), S (fricativa) e CV [nasal]. Importante relembrar que, à exceção da palavra COSTA registrada ortograficamente desde o início pelas crianças Marina e Sônia, nenhuma das outras palavras CVC ou CV[nasal] foram registradas adequadamente no pré-teste aplicado antes do início das sessões. Ainda vale ressaltar que, mesmo Camila, que não consolidou os registros das correspondências focalizadas no presente artigo, apresentou um avanço na representação da escrita, ou seja, demonstrou, por meio de suas escritas, progressão na compreensão do princípio alfabético.

Um dos objetivos deste artigo foi analisar as mediações ou tipos de scaffolding utilizados nas sessões, de modo que pudéssemos verificar estratégias que favoreceram a apropriação da escrita pelas crianças. Por meio da transcrição e análise das sessões, identificamos 7 principais tipos de scaffolding (Gestão, Instrução, Indagação, Sinalização, Elaboração, Reelaboração e Avaliação), bem como subcategorias (participação, operação, inferência, confirmação, explicação, tarefa/ 
ação, registro, pista, correção, síntese e feedback positivo) e ainda verificamos os momentos e a frequência nas três sessões analisadas. Como resultados da pesquisa, pudemos perceber que houve um predomínio das interações verbais interrogativas e a Indagação foi o tipo de scaffolding mais utilizado, com suas subcategorias inferência, confirmação e explicação. Dentre estas, as estratégias de inferência, ou seja, de questões que o mediador fazia tendo em vista facilitar a elaboração de inferências sobre os sons envolvidos na escrita da palavra foi a mais recorrente.

A sinalização aparece em segundo lugar, com um número significativo de interações verbais direcionadas para a realização de alguma ação voltada para a execução da tarefa, com predomínio de sinalizações referentes ao registro da escrita no papel, tais como comparar a escrita com outro grupo, verificar se está faltando alguma letra. Interessante destacar que essa estratégia quase não aparece nas últimas sessões, na medida em que as crianças passaram a registrar no papel a escrita, e não mais a mediadora.

Além da categoria de gestão, que se refere prioritariamente ao papel do mediador de organizar a participação das crianças durante a escrita das palavras de modo a envolvê-las na tarefa e promover um trabalho cooperativo, e as instruções operacionais, com vistas a esclarecer as regras de funcionamento do grupo, percebeu-se que a categoria de elaboração, em que se fornecem pistas fonológicas para as crianças analisarem a palavra oralmente, também se revelou importante no processo.

No que se refere à frequência das interações verbais, os dados revelam que o scaffolding, ou seja, o conjunto de estratégias utilizadas pelo adulto para dar assistência ao desenvolvimento das crianças, foi significativamente menor nas últimas sessões, com diminuição progressiva das interações verbais (categorias elencadas). Uma vez que as crianças, ao consolidar uma determinada aprendizagem, passam a utilizá-la com autonomia, o que é desejável no processo de apropriação da língua escrita, isso foi reafirmado nas análises das sessões de escrita inventada.

Sabemos que essas intervenções se deram em espaço privilegiado de pesquisa, com número pequeno de crianças por grupo, mas entendemos que as estratégias de scaffolding podem ser apropriadas pelos professores e usadas em suas salas de aula na medida em que compreenderem os tipos de mediações que são importantes e podem suscitar o avanço na escrita das crianças. O formato pode ser variado: em pequenos grupos ou em análise coletiva de palavras, mas 
os princípios que regem essas mediações no processo da escrita de palavras podem ser utilizados e redimensionados na diversidade de situações que ocorrem no dia a dia das salas de aula de alfabetização.

\section{REFERÊNCIAS}

ALVES MARTINS, M., SALVADOR, L. e ALBUQUERQUE, A. Análise qualitativa dos efeitos de um programa de intervenção de escrita inventada na evolução da escrita de crianças em idade pré-escolar. Actas do $12^{\circ}$ Colóquio de Psicologia e Educação. Lisboa: Instituto Universitário de Ciências Psicológicas, Sociais e da Vida/ISPA, 21 a 23 de junho de 2012.

ALVES MARTINS, M., ALBUQUERQUE, A., SALVADOR, L. e SILVA, C. Escrita Inventada e aquisição da leitura em crianças de idade pré-escolar. Psicologia: Teoria e Pesquisa, vol. 31, no. 2, p. 137-144, abr-jun.2015.

ALVES MARTINS, M., SALVADOR, L., ALBUQUERQUE, A. e FERNANDÉZ, M. M. "Outro niño lo escribió así". Ayuda educativa Y resultados de atividades de escritura inventada. Revista de Educación, 377, p. 161-168, julio-septiembre, 2017.

ALVES MARTINS, M., ALBUQUERQUE, A. Habilidades iniciais de alfabetização em Português: Pesquisa Transcultural em Portugal e no Brasil. Psico-USF, Bragança Paulista, v.22, n.3, p. 437-448, set/dez.2017. (b)

FERrEiro, E. e TEBEROSKY, A. Psicogênese da Língua Escrita. Porto Alegre: Artmed, 1985.

FERREIRO, E. O ingresso na escrita e nas culturas do escrito: seleção de textos de pesquisa. São Paulo: Cortez, 2013.

MOLL. Vygostky e a Educação. Implicações Pedagógicas da psicologia sócio-histórica. Porto Alegre: Artes Médicas, 1996.

PONTECORVO, C. Discutir, argumentar e pensar na escola. O adulto como regulador da aprendizagem. In: PONTECORVO, C., ALEJO, A.M. \& ZUCCHERMAGLIO, C. (Ed.) Discutindo se aprende: Interação social, conhecimento e escola (p.65-88). Porto Alegre: Artmed Editora, 2005.

TEBEROSKY, A. Los conocimientos prévios del niño sobre el lenguaje escrito y su incorporacion al aprendizaje escolar del ciclo inicial. Revista de educación, n. 288. Alfabetización, Universidad de la Rioja, 1989.

SALVADOR, L. Aprender a ler, escrevendo: Impacto de um programa de escrita na leitura de crianças do $1^{\circ}$ ano do E.B. em risco de desenvolver dificuldades de aprendizagem. Lisboa, ISPA, 2017. (tese doutorado)

SPINILLO, A. G.; LAUTERT, S. L. Pesquisa-intervenção em psicologia do desenvolvimento cognitivo: Princípios metodológicos, contribuição teórica e aplicada. In: CASTRO, L. R.; BESSET, V. L.(org.). Pesquisa-intervenção na infância e juventude. Rio de Janeiro: NAU, 2009 P.294-321.

SOARES, M. Alfabetização: a questão dos métodos. São Paulo: Contexto, 2016.

VYGOTSKY, L. S. A formação social da mente: o desenvolvimento dos processos 
psicológicos superiores. 7a edição. São Paulo: Martins Fontes, 1991.

VYGOTSKY, L. S. Pensamento e Linguagem. Edição eletrônica: Ed Ridendo Castigat Mores, 2001.

WOOD, D., B., JS., \& ROSS, G. The role of tutoring in problem solving. Journal of Child Psychology and Psychiatry, and Allied Disciplines. 17 (2) 1976 p.89-100.

\section{NOTAS}

1 A pesquisa de pós-doutorado intitulada "A mediação na escrita inventada de palavras compostas por sílabas CCV e CVC por crianças que apresentam hipóteses silábico-alfabética e alfabética" foi desenvolvida pela profa. Valéria Barbosa de Resende sob supervisão de Margarida Alves Martins, professora Catedrática de Psicologia da Educação do Instituto Universitário Ciências Psicológicas, Sociais e da Vida - ISPA/Lisboa, Portugal. A referida pesquisa foi aprovada pelo Comitê de Ética em Pesquisa (CEP/UFMG), tendo parecer consubstanciado de aprovação emitido em 24/09/2018.

2 CV[nasal] é a nomenclatura usada por Soares (2016) para se referir à consoante nasal pós-vocálica, marcada por 'N' ou 'M'. Alguns linguistas consideram essa consoante como a coda nas estruturas silábicas CVC; "para outros, ela não faz parte da estrutura silábica, ligando-se diretamente ao núcleo da sílaba" (SOARES, 2016, p.312).

3 Tarsis Matarelle é aluna do curso de Pedagogia da FaE/UFMG e participou da aplicação das avaliações escritas, realizou as filmagens e produziu registros de cada sessão do Programa de Escrita Inventada.

4 Os nomes das crianças são fictícios.

5 Princípio acrofônico diz respeito à relação entre o nome da letra e sua correspondência ao fonema que a letra representa, por exemplo, letra V, nome da letra "vê".

Submetido: 20/06/2019

Aprovado: 17/10/2019

Contato:

Valéria Barbosa de Resende

Universidade Federal de Minas Gerais (UFMG)

Campus Pampulha

Faculdade de Educação Avenida Antônio Carlos, no 6.627

Belo Horizonte $|\mathrm{MG}|$ Brasil

CEP 31.270-901 